\title{
Hemangioendothelioma of the Mouse Thyroid Gland
}

National Cancer Institute

\section{Source}

National Cancer Institute. Hemangioendothelioma of the Mouse Thyroid Gland. NCI

Thesaurus. Code C134958.

A neoplasm that arises from vascular endothelium and occurs in the thyroid gland of a mouse. 